\title{
Flooded-area satellite monitoring within a Ramsar wetland Nature Reserve in Argentina
}

\author{
Anabella Ferral ${ }^{1,2}$, Eduardo Luccini $^{3,4, *}$, Alejandro Aleksinkó ${ }^{5}$, Carlos M. Scavuzzo ${ }^{1}$ \\ ${ }^{1}$ Instituto Gulich, Universidad Nacional de Córdoba-CONAE, Centro Espacial Teófilo Tabanera, \\ Ruta 45 km 8, Falda del Cañete, 5187 Córdoba, Argentina. \\ ${ }^{2}$ Cátedra UNESCO en Seguridad Humana y Desarrollo Regional \& CIADE-CdA, Universidad Blas \\ Pascal, Av. Donato Alvarez 380, 5000 Córdoba, Argentina. \\ ${ }^{3}$ CONICET, Centro de Excelencia en Productos y Procesos de Córdoba (CEPROCOR), Sede Santa \\ María de Punilla, Pabellón Ceprocor, X5164 Córdoba, Argentina. \\ ${ }^{4}$ Pontificia Universidad Católica Argentina, Facultad de Química e Ingeniería del Rosario, Av. \\ Pellegrini 3314, 2000 Rosario, Argentina. \\ ${ }^{5}$ Secretaría de Recursos Hídricos y Coordinación de la Provincia de Córdoba, Humberto Primo 607 , \\ 5000 Córdoba, Argentina.
}

\footnotetext{
* Corresponding author: Dr. Eduardo Luccini. CONICET, Centro de Excelencia en Productos y Procesos de Córdoba (CEPROCOR), Sede Santa María de Punilla, Pabellón Ceprocor, X5164 Córdoba, Argentina. Tel: +54 3541 48-9651/53. Fax: +54 3541 48-8181. e-mail: eluccini@ceprocor.uncor.edu
} 


\section{Abstract}

The protection and restoration of water-related ecosystems is one of the goals to be achieved by the United Nations' 2030 Agenda for Sustainable Development. In this framework and requested by government Argentine institutions concerned with water, biodiversity and territorial management, this study analyzes the evolution of the flooded area within the Dulce River wetlands and Mar Chiquita Lake Nature Reserve (centered around $30.6^{\circ} \mathrm{S}, 62.6^{\circ} \mathrm{W}, 70 \mathrm{~m}$ above sea level) in Argentina since 2003, when the historical maximum extent was reached, until 2017. The Modified Normalized Difference Water Index (MNDWI) was calculated on atmospherically corrected NASA Landsat 5 Thematic Mapper (L5-TM) and Landsat 8 Operational Land Imager (L8-OLI) reflectance data over two-scene cloudless-sky mosaics to cover the whole Reserve. Mixed-water pixels constituted an important fraction of the total-water covered area, particularly during years of minimum water level in Mar Chiquita Lake. So, MNDWI values were analyzed along transects crossing two stable regional water bodies to determine precise thresholds for detection of non-water (MNDWI $<-0.15$ for L5-TM, MNDWI $<-0.35$ for L8-OLI), mixed-water $(-0.15<$ MNDWI $<0.4$ for L5-TM, $-0.35<$ MNDWI $<0.5$ for L8-OLI) and open-water (0.4 < MNDWI for L5-TM, $0.5<$ MNDWI for L8-OLI) pixels. A higher spatial resolution image, SPOT5-HGR2, was used to validate the classification method. A confusion matrix was built which resulted in an overall accuracy of $99.2 \%$ and a Kappa coefficient of 0.98 . In-situ Geo-referenced photographic registers were also taken simultaneously to a Landsat 8 overpass to confirm the classification thresholds. The analysis of simulated MNDWI response, by using the assumption of the linear mixture model, showed that mixed pixels should present from $9 \%$ to $76 \%$ of detectable open-water area. Maximum total flooded area extensions of about $3600 \mathrm{~km}^{2}$ by $2003-2005$ and a minimum one of $2050 \mathrm{~km}^{2}$ by the end of 2011 were established, followed by a recent trend to the recovering with a total flooded area of about $3400 \mathrm{~km}^{2}$ in the period 2015-2017. Open-water covered area follows closely the behavior of in-situ water level 
measurements of Mar Chiquita Lake, showing a maximum in year 2003 and a minimum towards the end of 2013, in a significant linear relation from which a topographical slope of the terrain of about $0.012 \%$ is inferred that agrees with previous bathymetric studies. Results show the powerful complement between a reliable water satellite monitoring tool and locally-measured parameters in so dynamic wetland regions.

Keywords: wetland; Landsat; MNDWI; mixed water 


\section{Introduction}

The changes in the extent of water over time on wetlands are an important indicator to be followed, as proposed by the Statistical Commission of the United Nations' 2030 Agenda for Sustainable Development, and remote sensing techniques appear as the best choice to be implemented (UN, 2017). Satellite sensors measurements become a crucial tool in the last decades for tracking different aspects of our planet. Measurements from a variety of wavelength channels, many of which are common to different satellite instruments, have been combined to define a series of specific indices characterizing parameters of interest. Referred to water bodies and particularly to the monitoring of wetlands, they were applied to a variety of subjects such as environmental assessment (e.g., Mozumder et al. 2014), water volume (Crétaux et al. 2016), hydrological dynamics and flooding (Chen et al. 2013; Sharma et al. 2014; Li et al. 2015; Wang et al. 2015). Since 1972, the National Aeronautics and Space Administration (NASA) Landsat satellite series have produced the longest continuous global record of the Earth's surface. Landsat 8, launched in February 2013, meant a success to assure continuity with Landsat 5 data which was decommissioned in June 2013. In this work, reflectance measurements from both Landsat 5 Thematic Mapper (L5-TM) and Landsat 8 Operational Land Imager (L8-OLI) sensors are used. The Modified Normalized Difference Water Index (MNDWI) (Xu 2006) is extensively employed from Landsat multispectral radiometers data for the identification of water bodies (e.g., Ji et al. 2009; Xu-kai et al. 2012; Chen et al. 2013; Sharma et al. 2014; Li et al. 2015; Wang et al. 2015). Particularly, Ferral et al. (2013) made one of the first adaptations of the MNDWI to the specific radiometric bands of L8-OLI. The identification of open water bodies from satellite imagery is at present a relatively simple task. However, the accurate delineation of lake shorelines or the determination of mixed pixels within wetlands is definitely more challenging, particularly if imagery from only one satellite is used for, and emphasis on this subject is made in the present work. 
The Dulce River wetlands and Mar Chiquita Lake in Argentina were declared Nature Reserve by Córdoba Province in 1994, and was incorporated in 2002 to the List of Wetlands of International Importance by the Ramsar Convention on Wetlands (http://www.ramsar.org/). Mar Chiquita is the biggest salt lake in Latin America. Studying their isotopic changes, Piovano et al. (2004) found that low water height levels prevailed during the 200 years previous to the 1970 's decade. Earlier registers around year 1900 allude to areas of about $1000 \mathrm{~km}^{2}$ (Bucher 2006, and references therein). In contrast, a predominantly positive hydrological balance has given a notable dynamics to the Mar Chiquita Lake water level during the last four decades (Piovano et al. 2002, 2004; Troin et al. 2010), reaching total open-water covered areas over $6000 \mathrm{~km}^{2}$. Several studies addressed different aspects on this system, about its geography (Reati et al. 1996), geochemical composition (Martínez 1995; Piovano 2002), fauna (Bucher 1992; Nores 2011), flora (Stutz and Prieto 2003) and hydrodynamics (Plencovich 2011). A complete review of the knowledge on the geography, biodiversity and history of this region was made by Bucher (2006).

Concerned by the complex evolution of the Dulce River wetlands and Mar Chiquita Lake and attending to its preservation, this research was requested by Argentine government institutions. Main concerns in this region are the Nature Reserve's ecosystem, the management of the real estate market pressure in their edge, and the hydrological balance in response to the pluvial influx from the northern rivers causing frequent flooding events on the principal cities on the south of Mar Chiquita Lake, mainly Miramar city. For this purpose, the flooded area behavior of the Dulce River wetlands within the Nature Reserve was analyzed spanning the period requested by the government authorities (2003-2017), correlating it with simultaneous locally measured water level of Mar Chiquita Lake whose database covers five decades since November 1967 up to the present. So, the analyzed period 2003-2017 includes the historical maximum water level around 2003 and the lowest minimum water level in forty years of 2013. 


\section{Materials and methods}

\subsection{Study area}

Figure 1-left presents the geographical location of the Dulce River wetlands and Mar

Chiquita Lake Provincial Nature Reserve on an official map, centered around $30.6^{\circ} \mathrm{S}, 62.6^{\circ} \mathrm{W}, 70 \mathrm{~m}$ above sea level (asl) in Córdoba Province (demarcated at bottom-left corner), Argentina. It is presently in process to be appointed as National Nature Reserve. Covering $9770.85 \mathrm{~km}^{2}$, it will be the largest of a total of 47 National Nature Reserves in Argentina. Including their tributaries, mainly the Dulce River at north, it is part of one of the largest endorheic systems in the world with a total extension of about $37500 \mathrm{~km}^{2}$ (Piovano et al. 2002; 2004). Official cartography can be found at http://www.recursoshidricos.gov.ar/webdrh/_docs/Poster_Sistema_Mar_Chiquita.pdf. The northern gray contour of the Nature Reserve in Figure 1-right (over a 2013 Landsat 8 mosaic in real colour, RGB-432 combination) highlights the area of study of this work and corresponds specifically to the Dulce River wetlands, a potentially flooded region of $7213.62 \mathrm{~km}^{2}$.
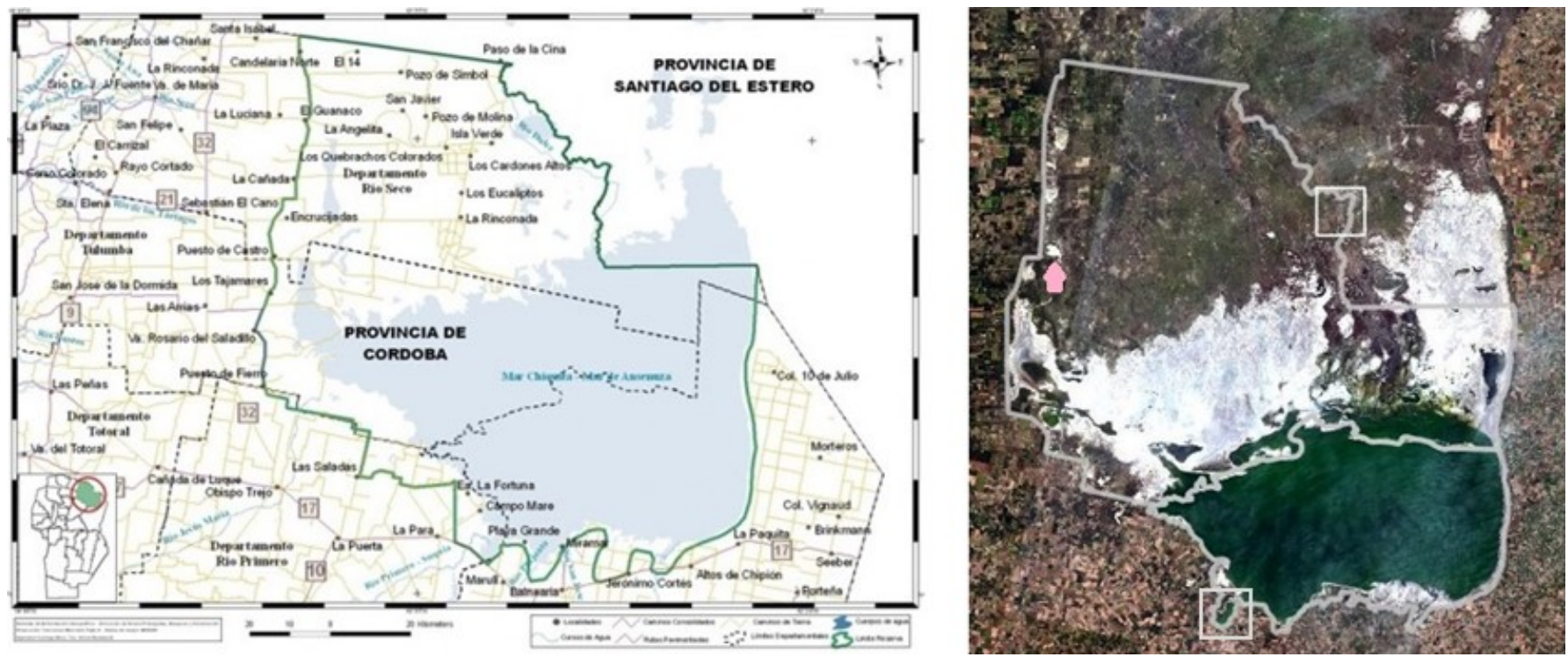

Figure 1. Left: Geographical location of the Dulce River wetlands and Mar Chiquita Lake Nature Reserve (demarked at bottom-left corner) in Córdoba Province, Argentina (source: Argentine Secretary of Environment). Right: The northern gray contour of the Nature Reserve corresponds to 
the potentially flooded area of Dulce River wetlands analyzed in the present study, highlighted over a 2013 Landsat 8 mosaic in real colour (RGB-432 combination). The southern gray contour is the region actually defined as Mar Chiquita Lake within the Nature Reserve. Rectangular contours correspond to Los Porongos lagoon and a South branch of Mar Chiquita Lake (called MC South Cove), sub-areas used to define the MNDWI thresholds for water pixels classification. The clear arrow on the Northwest border indicates the site where ground photographic registers were taken to validate the satellite pixel classification.

The southern grey contour in Figure 1-right is the region actually defined as Mar Chiquita Lake within the Nature Reserve, with a surface of $2557.23 \mathrm{~km}^{2}$ whose limit is defined by a salty crustal contour observed at a water level of about $66 \mathrm{~m}$ asl typical until year 1976, when the period of big floods started. The rectangular contours in Figure 1-right demark the sub-areas of Los Porongos lagoon (northern rectangle) and a South branch of Mar Chiquita Lake (MC South Cove, southern rectangle) used to establish the MNDWI thresholds for the satellite pixels classification. The clear arrow on the Northwest border indicates the zone where a field photographic campaign was made as a complement to validate the satellite classification.

\subsection{Satellite data}

Orbits of both L5 satellite (March 1984 to January 2013) and L8 satellite (active since February 2013) are circular, sun-synchronous, near-polar at an altitude of $705 \mathrm{~km}$ asl. They each cross the equator from north to south at 10:00 am \pm 15 minutes local time on each pass to provide maximum illumination with minimum water vapour present (haze and cloud build-up), making an orbit in about 99 minutes, completing over 14 orbits per day, and covering the same area on the Earth every 16 days, so that about two images a month are available of a given place. Table 1 shows the characteristics of both L5-TM and L8-OLI sensors. 


\begin{tabular}{lccc}
\hline Sensor & Band & Spectral range $[\mu \mathrm{m}]$ & Spatial resolution $[\mathrm{m}]$ \\
\hline L5-TM & B1 & $0.45-0.52$ & 30 \\
& B2 & $0.52-0.60$ & 30 \\
& B3 & $0.63-0.69$ & 30 \\
& B4 & $0.76-0.90$ & 30 \\
& B5 & $1.55-1.75$ & 30 \\
& B6 & $10.40-12.50$ & 120 \\
& B7 & $2.08-2.35$ & 30 \\
\hline \multirow{2}{*}{ 8-OLI } & B1 & $0.435-0.451$ & 30 \\
& B2 & $0.452-0.512$ & 30 \\
& B3 & $0.533-0.590$ & 30 \\
& B4 & $0.636-0.673$ & 30 \\
& B5 & $0.851-0.879$ & 30 \\
& B6 & $1.566-1.651$ & 30 \\
& B7 & $2.107-2.294$ & 15 \\
& B8 & $0.503-0.676$ & 30 \\
\hline
\end{tabular}

Table 1. Spectral range and spatial resolution of each band $(\mathrm{B} \#)$ of Landsat 5 Thematic Mapper (L5TM) and Landsat 8 Operational Land Imager (L8-OLI) sensors. Temporal frequency at a fixed location on the Earth's surface is 16 days.

To build the mosaic covering the whole Nature Reserve under study, two scenes from adjacent satellite paths are needed. Both scenes are separated by at least one week in time and they must present a cloudless-sky, limiting the availability of dates to analyze. Selected atmosphericallycorrected, geo-referenced and ortho-rectificated images used in this work, provided by the United States Geological Survey, are detailed in Table 2. Specific details about these products can be found in the Landsat 4-7 Surface Reflectance product guide (https://landsat.usgs.gov/sites/default/files/documents/ledaps_product_guide.pdf) and Landsat 8 Surface Reflectance Code (LASRC) product guide (https://landsat.usgs.gov/sites/default/files/documents/lasrc_product_guide.pdf). A SPOT 5-HGR2 image from the Argentine National Commission for Space Activities (CONAE) catalogue was used to perform the main validation procedure as it is explained in the next section. 


\begin{tabular}{|c|c|c|}
\hline Year of mosaic & Sensor & Scene's date \\
\hline 2003 & L5-TM & $\begin{array}{l}\text { December } 102003 \\
\text { December } 172003\end{array}$ \\
\hline 2004 & L5-TM & $\begin{array}{l}\text { May } 022004 \\
\text { May } 092004\end{array}$ \\
\hline 2005 & L5-TM & $\begin{array}{l}\text { March } 252005 \\
\text { April } 032005\end{array}$ \\
\hline 2006 & L5-TM & $\begin{array}{l}\text { March } 052006 \\
\text { March } 122006\end{array}$ \\
\hline 2007 & L5-TM & $\begin{array}{l}\text { February } 042007 \\
\text { February } 112007\end{array}$ \\
\hline 2008 & L5-TM & $\begin{array}{l}\text { October } 202008 \\
\text { October } 272008\end{array}$ \\
\hline 2009 & L5-TM & $\begin{array}{l}\text { May } 162009 \\
\text { May } 232009\end{array}$ \\
\hline 2010 & L5-TM & $\begin{array}{l}\text { February } 032010 \\
\text { February } 122010\end{array}$ \\
\hline 2011 & L5-TM & $\begin{array}{l}\text { March } 032011 \\
\text { March } 102011\end{array}$ \\
\hline 2011 & L5-TM & $\begin{array}{l}\text { September } 272011 \\
\text { October } 202011\end{array}$ \\
\hline 2013 & L8-OLI & $\begin{array}{l}\text { April } 162013 \\
\text { April } 252013\end{array}$ \\
\hline 2014 & L8-OLI & $\begin{array}{l}\text { January } 222014 \\
\text { January } 132014\end{array}$ \\
\hline 2015 & L8-OLI & $\begin{array}{l}\text { September } 062015 \\
\text { September } 132015\end{array}$ \\
\hline 2016 & L8-OLI & $\begin{array}{l}\text { February } 292016 \\
\text { February } 042016\end{array}$ \\
\hline 2017 & L8-OLI & $\begin{array}{l}\text { March } 192017 \\
\text { April } 112017\end{array}$ \\
\hline 2017 & L8-OLI & $\begin{array}{l}\text { September } 112017 \\
\text { September } 182017\end{array}$ \\
\hline
\end{tabular}

Table 2. Specifications of the satellite scenes selected in cloudless-sky days along the period 20032017 to analyze the extension of the flooded area on the Dulce River wetlands. Each mosaic is 
constructed from two close-in-date and partially overlapping scenes belonging to satellite paths $228 / 229$ and row 81 .

\subsection{Satellite data processing}

Satellite reflectance data were processed with Environment for Visualizing Images (ENVI) software version 4.2 (HGS 2016). The Modified Normalized Difference Water Index (MNDWI) is defined as:

$$
M N D W I=\frac{r_{\text {green }}-r_{\text {SWIR }}}{r_{\text {green }}+r_{\text {SWIR }}}
$$

where $r_{\text {green }}$ and $r_{\text {SWIR }}$ are the reflectance registered from a given direction by the sensor in the green and short-wave infrared ranges respectively (Xu 2006). The MNDWI takes values in the range $[-1,1]$ and works reliably for any multispectral sensor with a green band between 0.5-0.6 $\mu \mathrm{m}$ (bands B2 for L5-TM and B3 for L8-OLI, see Table 1) and a SWIR band between 1.55-1.75 $\mu \mathrm{m}$ (bands B5 for L5TM and B6 for L8-OLI, see Table 1), enhancing open-water features for which MNDWI values arrange in a positive mode, while suppressing noise from built-up land, vegetation, and soil whose MNDWI values group in a marked negative mode (e.g., HGS 2016). The MNDWI thresholds to separate open-water pixels, mixed-water pixels and non-water pixels were obtained through a boxplot analysis of MNDWI values along transects crossing two stable water bodies in the region (Figure 1-right).

\subsection{Classification's precision assessment}

A SPOT 5-HRG2 CNES image (spatial resolution 10 m) from 08 April 2018, scene 687/410 was analyzed, using the same thresholds of Table 3 for L8-OLI, to extract check points to be used as ground truth. A confusion matrix was developed to characterise the open-water, mixed-water and 
non-water pixels classification. Overall accuracy and Kappa coefficient were calculated to assess the accuracy according to equations (e.g. Congalton and Green 1999):

$$
\begin{aligned}
& \text { Overall accuracy }=\frac{T P+T N}{T} \\
& \text { Kappa coefficient }=\frac{T *(T P+T N)-\Sigma}{T^{2}-\Sigma}
\end{aligned}
$$

where TP is the number of correctly classified water pixels, TN is true negative (the number of correctly rejected non-water pixels), $\mathrm{T}$ is the total number of evaluated pixels, $\Sigma$ is the chance accuracy represented by $(\mathrm{TP}+\mathrm{FP})(\mathrm{TP}+\mathrm{FN})+(\mathrm{FN}+\mathrm{TN})(\mathrm{FP}+\mathrm{TN}), \mathrm{FN}$ is false negative (the number of undetected water pixels) and FP is false positive (the number of incorrectly extracted water pixels). In addition, photographic registers were taken within the study zone (Figure 1-right) in simultaneous with a Landsat 8-OLI overpass during April 2015, as a complement to assess the precision of the classification.

\subsection{Water level data}

Water height level data of Mar Chiquita Lake are correlated with the satellite-retrieved flooded area. They are daily measured by the Secretaría de Recursos Hídricos y Coordinación de la Provincia de Córdoba, Argentina, continuously since November 1967 through a calibrated bar stocked in the lake (e.g. Vargas 2014). 


\section{Results and discussion}

\subsection{Mar Chiquita water level dynamics}

Figure 2 presents the monthly average water height level of Mar Chiquita Lake for the period 1967-2017, noting that it developed a marked dynamical character during the last four decades given the mentioned predominantly positive hydrological balance in its basin (Piovano et al. 2004; Troin et al. 2010).

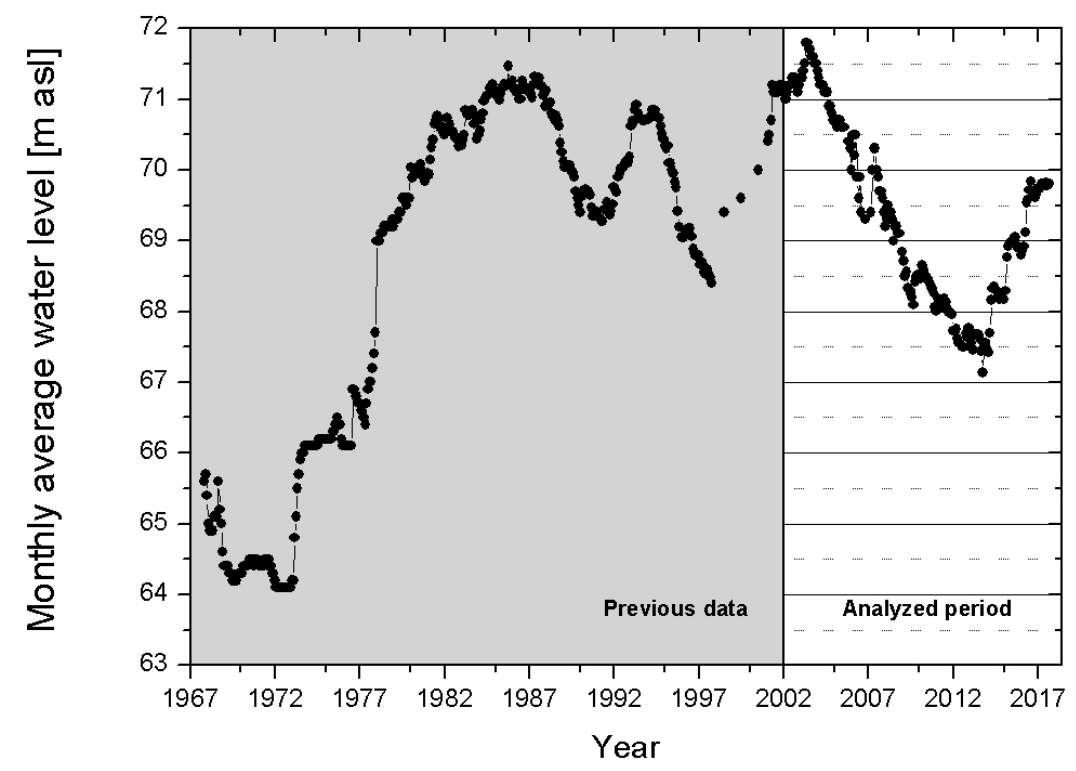

Figure 2. Complete time series of monthly-averaged daily measurements of Mar Chiquita Lake water level, from November 1967 to September 2017. Data analyzed in the present work cover the period 2003-2017.

Since the start of in-situ water level measurements in 1967, the lowest level occurred in 1972 with $64.1 \mathrm{~m}$ asl, followed by a systematic increase and an oscillating period afterwards. This work addresses the analysis of the period 2003-2017 which is signed by two roughly linear-in-time steps: the decreasing trend after the historical absolute maximum in May 2003 from a level of $71.8 \mathrm{~m}$ asl down to a minimum of $67.1 \mathrm{~m}$ asl in October 2013, followed by a recent progressive recovery 
reaching a level of $69.8 \mathrm{~m}$ asl in September 2017. As it was referred to, water levels higher than about $66 \mathrm{~m}$ asl imply flooded area in the surroundings of Mar Chiquita Lake, and they constitute the main subject of analysis in this work.

\subsection{Satellite pixel classification}

The whole Dulce River wetlands region analyzed in this work is topographically flat and it basically lacks of artificial features, so it is free of mountains' shadows and urban areas that often cause misclassification of water mapping due to similar reflectance patterns (Feyisa et al. 2014; Verpoorter et al. 2012). Two sub-areas, whose contours remain basically stable during long periods of time, were selected to define the MNDWI thresholds for pixel classification: Los Porongos lagoon (Figure 1-right and observed in detail in Figure 3-top) and MC South Cove (Figure 1-right and observed in detail in Figure 3-bottom). The detection of mixed-water pixels composed by soil and/or vegetation with a given percentage of water is a more complex subject when data from only one sensor are used. A deeper analysis of moist soil and mixed pixels would request complementary data such as synthetic aperture radar (SAR) measurements (e.g. Xiao et al. 2014; Mitchell et al. 2015) which are not in the scope of this work. Other studies for biodiversity monitoring include the complement with atlas of habitat-specific plant species (e.g. Kosicki and Chylarecki 2013), essential biodiversity variables (Vihervaara et al. 2017), etc. Evidently, MNDWI for mixed pixels will take intermediate values between the positive and the negative mode of the distribution, and a variety of approaches have been implemented in previous studies to define these thresholds (e.g. Acharya et al. 2016; Jones, 2015; Ho et al. 2011, 2010; Ji et al. 2009). As this work deals with flooded areas, the identification of mixed pixels is crucial. For this purpose, MNDWI values were analyzed for all dates listed in Table 2 along straight-line transects crossing Los Porongos lagoon and MC South Cove (highlighted over the MNDWI images in Figure 3-right). 

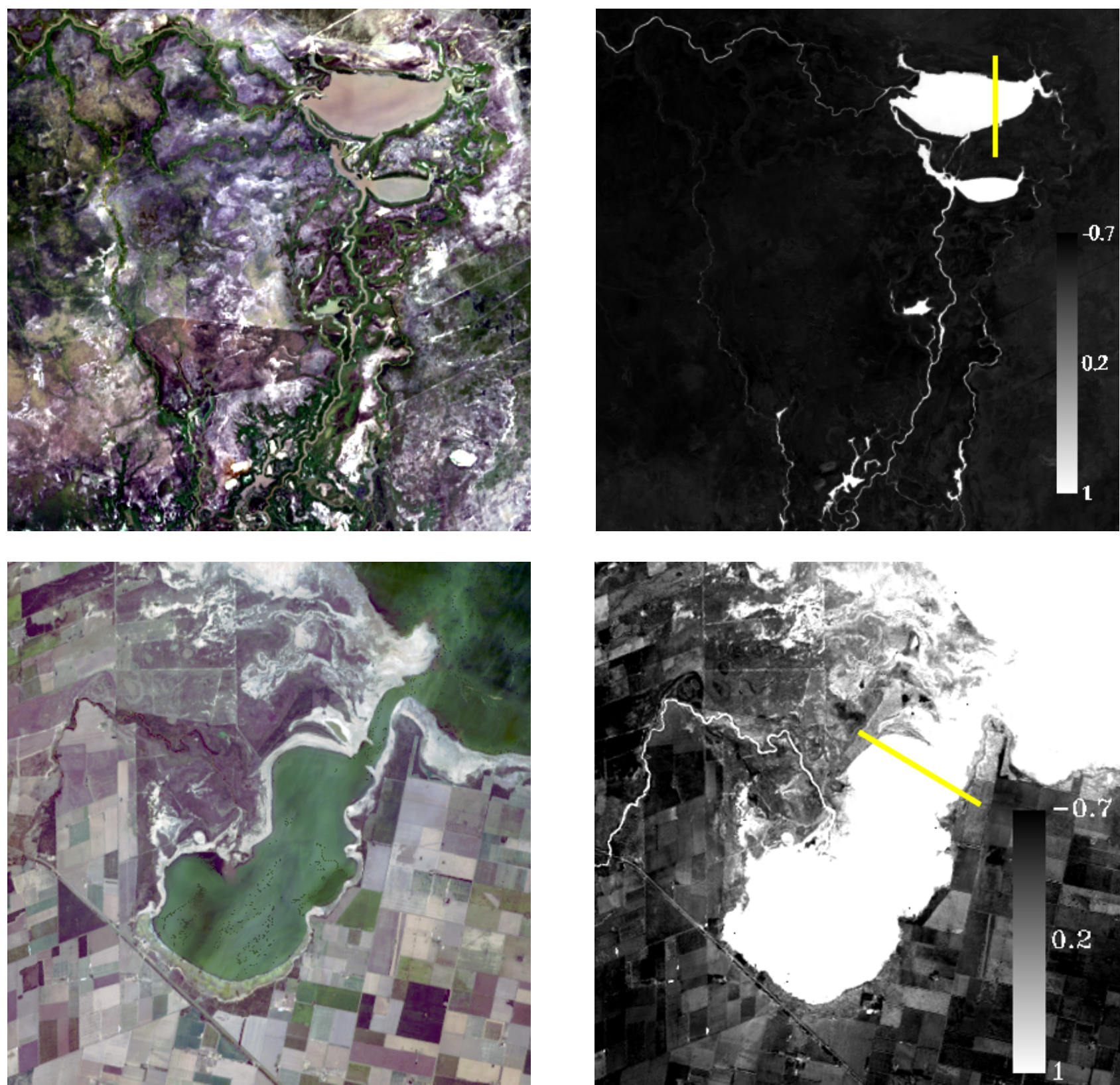

Figure 3. Sub-area of the L8-OLI 2013 image corresponding to Los Porongos lagoon (Top, upper rectangular contour in Figure 1-right) and MC South Cove (Bottom, lower rectangular contour in Figure 1-right) used to determine the criteria for water pixel classification. Left: real colour (RGB432). Right: MNDWI image where water areas stand out in light tones. Geographical transects used to determine the MNDWI thresholds are demarked as yellow segments over both water bodies.

The MNDWI pixel values along the transects for the sixteen available dates (listed in Table 2) of L8-OLI and L5-TM scenes are plotted in Figure 4, assuring a contrast between water and nonwater pixels which are separated by a steep transition from land to open water in the rather stable water body's borders, leaving an intermediate range of MNDWI values that can be considered as 
mixed pixels. In Figure 4, some peaks on the terrain at both sides of Los Porongos lagoon are consistent with the presence of temporary streams or non-permanent small pools between scrubland appearing during rainy periods. These pixels had no incidence since they were excluded from the analysis, as explained bellow.
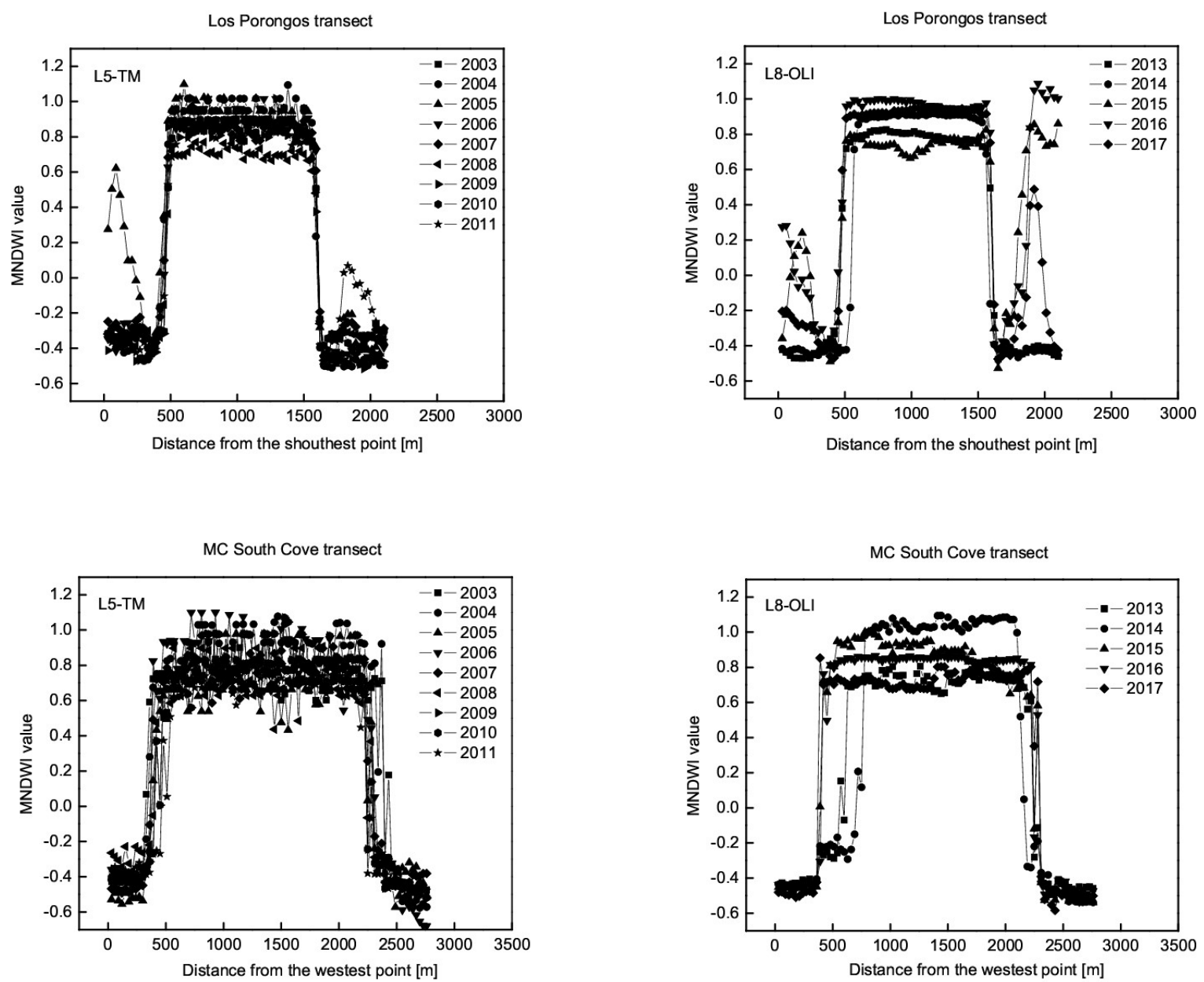

Figure 4. MNDWI values as a function of distance from a starting point along both transects of Figure 3, for the scenes covering the whole range of dates of Table 2. Top: Los Porongos transect (South-North direction). Bottom: MC South Cove transect (West-East direction). Left: Landsat 5TM data. Right: Landsat 8-OLI data.

The MNDWI thresholds to separate mixed-water pixels from open-water pixels and nonwater pixels were obtained through a box-plot analysis, observed in Figure 5- left for Landsat 5 TM, Figure 5- right for Landsat 8-OLI. It results from the "horizontal" sections with small variability of 
MNDWI values from Figure 4, associating lower values to non-water pixels and higher values to open-water pixels, excluding those pixels along the jump of transition and those mentioned peaks on the terrain belonging to non-permanent pools and streams. From Figure 5, the MNDWI box plots corresponding to open-water pixels and non-water pixels are well separated for both sensors, and TStudent test was performed to compare their mean values which resulted significantly different with $95 \%$ of confidence $(p<0.05)$ in both cases. In Figure 5, horizontal dashed lines indicate the thresholds that represent the mixed-water pixels range for both sensors. They are detailed in Table 3 .
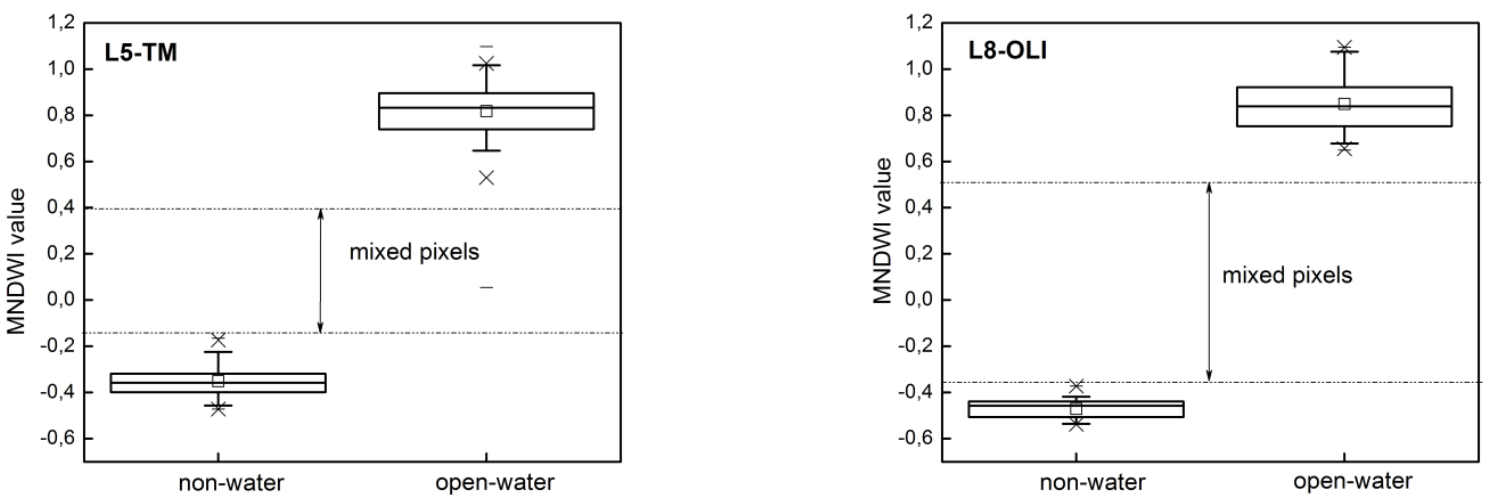

Figure 5. Box-plot analysis of MNDWI values for definite conditions of open-water and non-water from all dates and both transects of Figure 4 that allow determining the thresholds for the classification of mixed-water pixels, demarcated as horizontal dash lines and also detailed in Table 3 . Left: from Landsat 5-TM data. Right: from Landsat 8-OLI data.

\begin{tabular}{lcc}
\hline Surface coverage & L5-TM MNDWI range & L8-OLI MNDWI range \\
\hline non-water & MNDWI $<-0.15$ & MNDWI $<-0.35$ \\
\hline mixed-water & $-0.15<$ MNDWI $<0.4^{\#}$ & $-0.35<$ MNDWI $<0.5$ \\
\hline open-water & $0.4<$ MNDWI ${ }^{\#}$ & $0.5<$ MNDWI \\
\hline
\end{tabular}

Table 3. Ranges of MNDWI values established to detect non-water pixels, mixed-water pixels, and open-water pixels in L5-TM and L8-OLI scenes (also shown in Figure 4). 
\# Only in the analysis of L5-TM mosaic of year 2008 the upper threshold was lowered to 0.25 in order to avoid sparse pixels identified as mixed-water within the open-water area of the main lagoon, probably due to strong wind causing waves in the water surface. The threshold of 0.25 was obtained testing the lowest tuned value that assured the correct classification for the totality of open-water pixels within the body of the lagoon.

In addition, Figure 6 distinguishes the ranges detailed in Table 3 on the histograms of MNDWI pixel values from the whole Los Porongos region for the February 2010 L5-TM image and for the April 2013 L8-OLI image. Figure 7 shows the classified images of Los Porongos region for both the L5-TM 2010 (Figure 7-top) and the L8-OLI 2013 (Figure 7-bottom), standing out the water bodies in black colour. Figure 7-left shows the mixed-water classified images, Figure 7-center shows the open-water classified images and Figure 7-right shows the total (open+mixed) water classified images. Once the number of water-representing pixels are counted, the total area covered by water within the study zone is obtained multiplying by the $900 \mathrm{~m}^{2}$ area of each pixel.

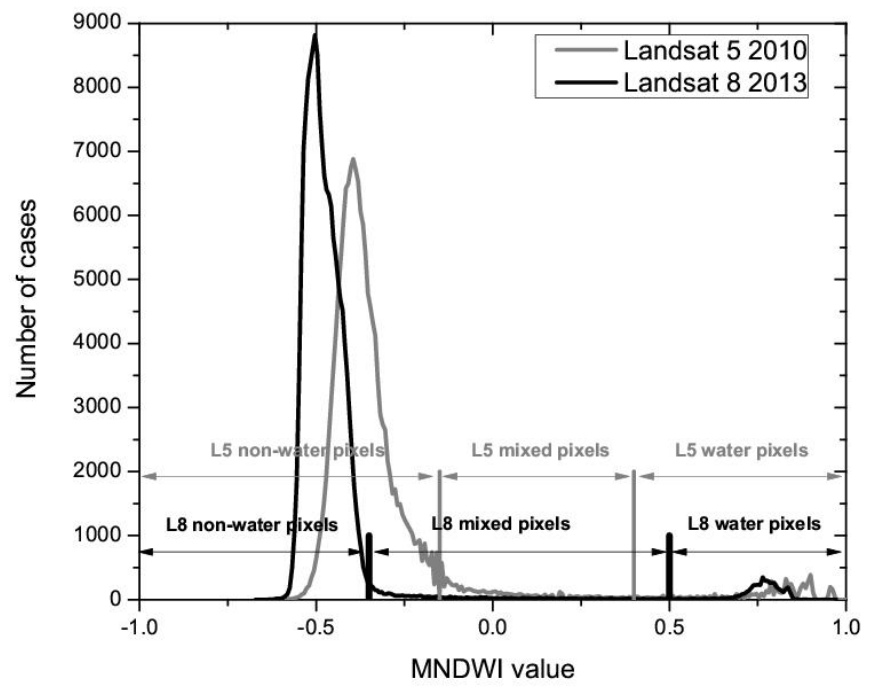

Figure 6. Histograms of MNDWI pixel values for the Landsat 5-TM 2010 and Landsat 8-OLI 2013 images from data of the whole Los Porongos lagoon region (upper rectangular contour in Figure 1right). Vertical lines denote the MNDWI thresholds established in Table 3 for the three cases: nonwater pixels, mixed-water pixels and open-water pixels. 


\subsection{Validation}

\subsubsection{Use of higher-resolution images}

Figure 8 shows cut-out images of Los Porongos lagoon from three sources with different spatial resolution: Landsat 8-OLI scene from April 162013 (Figure 8-left), SPOT5-HGR scene from 08 April 2013 with a spatial resolution of 10 m (Figure 8-center) and a cut-out from Google Earth platform corresponding to a CNES Airbus image from 2018, with a spatial resolution of $0.5 \mathrm{~m}$ (Figure 8-right). Check points were extracted from the SPOT image, close in date to assure that

Figure 7. Classified images of Los Porongos lagoon region according to the MNDWI ranges defined in Table 3. Top: Landsat 5, 12 February 2010. Bottom: Landsat 8, 25 April 2013. Left: mixed-water pixels. Center: open-water pixels. Right: total (mixed+open) water pixels.

LANDSAT 52010

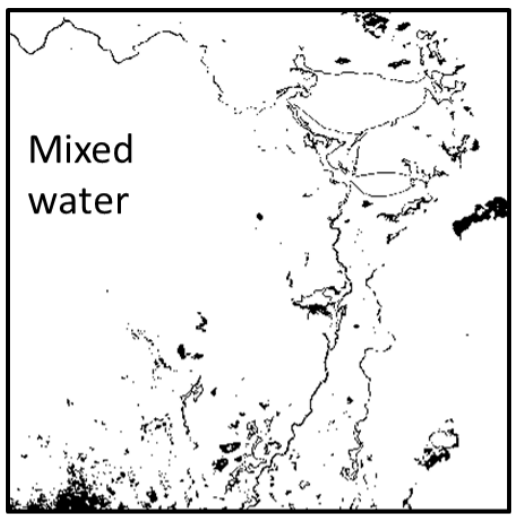

LANDSAT 82013

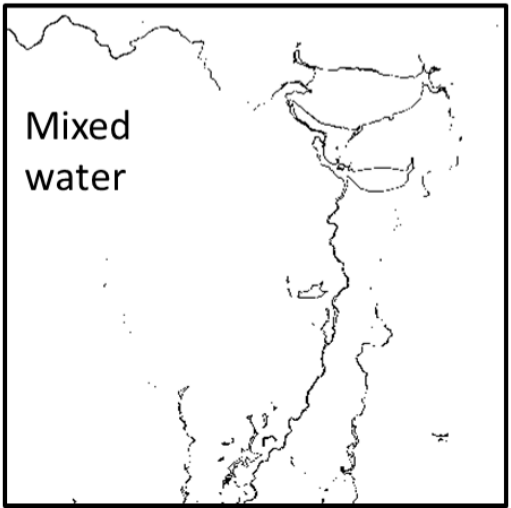

Open

water

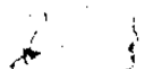

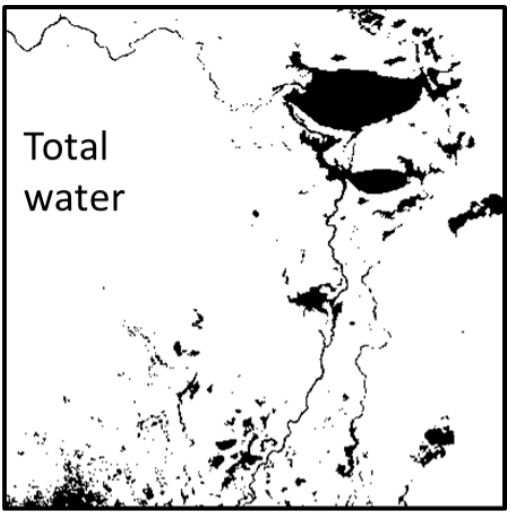

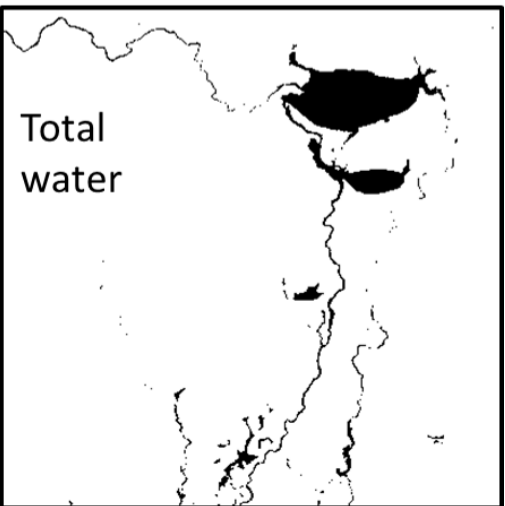


changes in water conditions on the ground between satellite acquisitions were minimized to validate the open-water, non-water and mixed-water Landsat 8-OLI classification. This is a very important issue since the water content over the flooding area in this region is highly variable and images too sparse in time do not allow feasible comparisons. So, given that we do not have access to dates close to Landsat 8-OLI passes for the highest spatial resolution CNES/Airbus image, it can't be used to extract check points. It was only used as a complement to observe details over the validation zone and to analyze MNDWI peaks at the boundaries of the lagoon along the transect used to determine the thresholds (Figure 3-top).

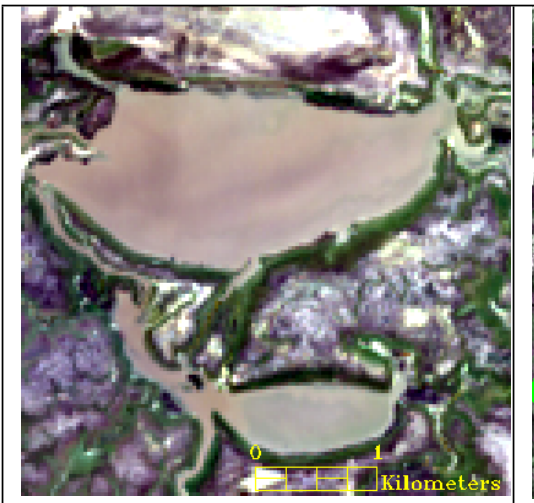

Landsat8-OLI, 16 April 2013. Scene: $228 / 81$. Spatial resolution: $30 \mathrm{~m}$

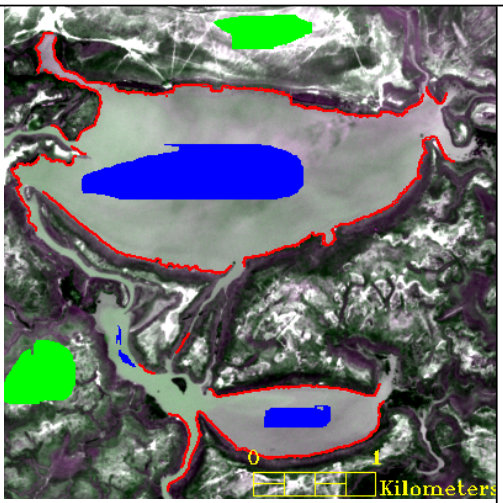

Spot5-HRG2, 08 April 2013. Scene: 687/410. Spatial resolution: $10 \mathrm{~m}$

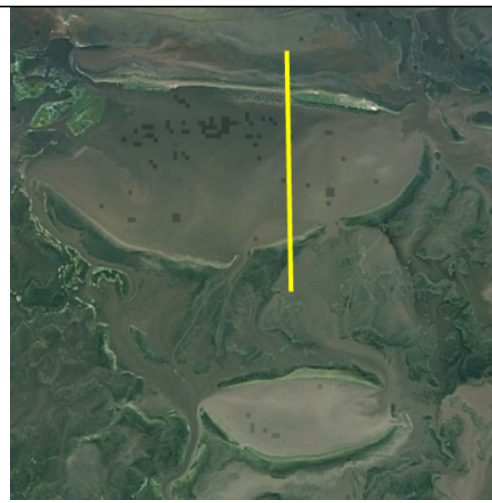

Google Earth, Image @ 2018

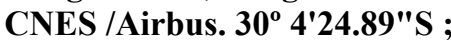
$6^{\circ} 33$ '58.11"O. Spatial resolution: $0.5 \mathrm{~m}$

Figure 8. Cut-out images of Los Porongos lagoon from three sources with different spatial resolution. Left: Landsat-8 OLI (RGB, 432) 16 April 2013 used as the test zone for validation. Center: SPOT 5-HGR2 (RGB, 121) 08 April 2013 used to select ground truth points: non-water pixels (green), open-water pixels (blue) and mixed-water pixels (red). Right: High spatial resolution Image (C) 2018 CNES /Airbus, taken from Google Earth facilities. Vertical yellow line corresponds to Los Porongos transect.

Figure 8-center shows the sampling check points selected from the SPOT image to be used as ground truth, where open-water pixels are coloured in blue, non-water pixels in green, and mixed pixels in red. Mixed-water pixels were selected point by point following the lagoon and river 
margins from the RGB (121) composite, while open-water and non-water areas were extracted as polygons. It is worth noting that, due to their different spatial resolution, nine pixels in a SPOT image cover the area of one pixel in a Landsat 8-OLI image. A total of 7938, 1701 and 4194 pixels were collected from the SPOT image as non-water, mixed pixels and open-water samples respectively, corresponding to 882, 189 and 466 control points in the Landsat 8-OLI scene (Figure 8left). Table 4 presents the confusion matrix results, showing excellent agreement with an overall accuracy of $99.2 \%$ (Equation 2) and a Kappa coefficient of 0.98 (Equation 3). Table 5 shows the commission and omission errors for each class. Non-water, mixed-water and open-water pixels present very small commission errors of $0.6 \%, 0 \%$ and $1.3 \%$ and omission errors of $0 \%, 6.4 \%$ and $0 \%$ respectively.

\begin{tabular}{lcccc}
\hline Class & \multicolumn{4}{c}{ Ground truth pixels taken from SPOT image } \\
\hline Non water & Open water & Mixed pixels & Total \\
\hline Unclassified & 0 & 1 & 0 & 1 \\
\hline Non water & 882 & 5 & 0 & 887 \\
\hline Mixed pixels & 0 & 177 & 0 & 177 \\
\hline Open water & 0 & 6 & 466 & 472 \\
\hline Total & 882 & 189 & 466 & 1537 \\
\hline
\end{tabular}

Table 4. Confusion matrix obtained from the SPOT image dated on 08 April 2013 at check sites shown in Figure 8-center and thresholds classification according to Table 3. Overall Accuracy $=99.2$ $\%$, Kappa coefficient $=0.98$.

\begin{tabular}{lcc}
\hline Class & Commission error (\%) & Omission error (\%) \\
\hline Non water & 0.6 & 0 \\
\hline Mixed pixels & 0 & 6.4 \\
\hline Open Water & 1.3 & 0 \\
\hline
\end{tabular}

Table 5. Commission and omission errors for each class of classification, resulting from the analysis of Table 4. 
where $f_{\text {non-water }}$ and $f_{\text {open-water }}$ correspond to the fraction of non-water area and open-water area respectively inside a pixel classified as mixed-water. Coefficients -0.45 and 0.80 are in fact the obtained Landsat 8-OLI mean values of the MNDWI distributions for these pure-content features (square symbols in the box-plots of Figure 5-right). Figure 9 presents simulated MNDWI Landsat 8OLI values calculated from the Equation 4, inferring that mixed-water pixels calculated using the thresholds of Table 3 should contain from about $9 \%$ to $76 \%$ of their area covered by open-water.

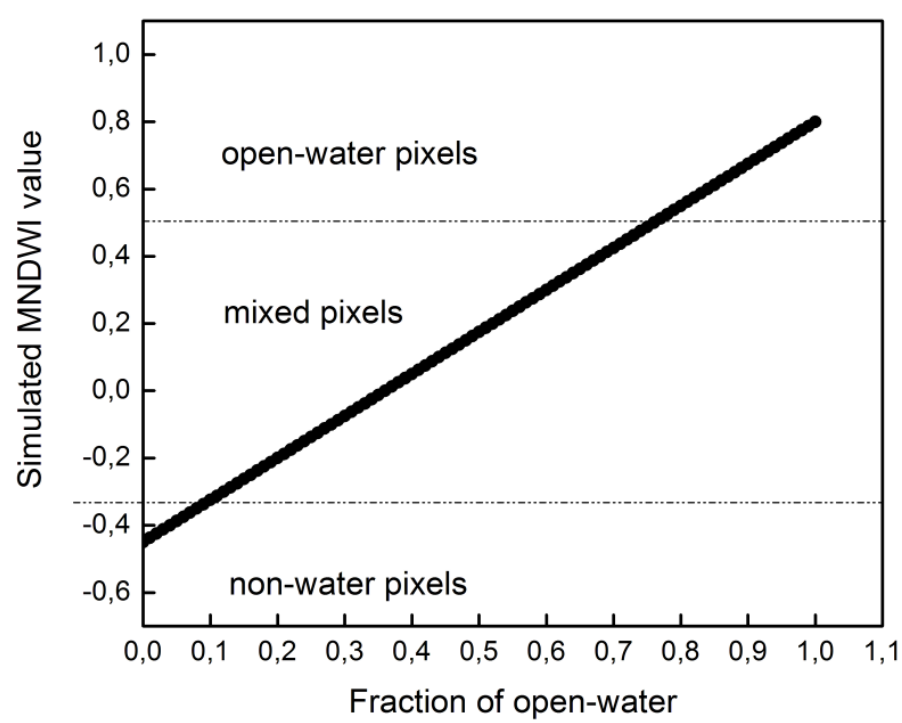


Figure 9. Simulated Landsat 8-OLI MNDWI values from the linear mixture model (Equation 4) which allows estimating the range of detectable open-water fraction of area inside a given pixel to be classified as mixed-water. They are demarked as dashed horizontal lines at open-water fractions of 0.09 and 0.76

To check the simulated MNDWI, the inner open-water content was analyzed in Landsat 8OLI pixels classified as mixed-water at the boundaries of Los Porongos lagoon by comparing with the classification (using the same thresholds than L8-OLI from Table 3) of the nine SPOT pixels contained in each Landsat 8-OLI pixel. Figure 10 a) shows a MNDWI image calculated for the SPOT5-HRG2 cut-out by using band 1 (centered at 545nm) and band 4 (centered at $1665 \mathrm{~nm}$ ).

Figure $10 \mathrm{~b}$ ) presents MNDWI values along Los Porongos transect for both sensors, L8-OLI and SPOT5-HRG2. It can be observed that jumps across the boundaries of Los Porongos lagoon appear at the same distance and mixed pixels for HRG2 sensor present a range between 0 and 0.55 .

Recently, Ogilvie et al. (2018) presented a semi-automated method to assess and optimize the potential of multi-sensor Landsat time series to monitor surface water extent and mean water availability over small water bodies in Tunisia. They used SPOT imagery and hydrometric field data of the period 1999-2014 for seven small reservoirs to calibrate MNDWI thresholds which resulted, out of other six water detection indices, to provide high overall accuracy and threshold stability during high and low floods. They obtained a mean surface area error below $15 \%$, attributed mainly to undetected narrow inlets on certain lakes. They propose an optimal threshold to delineate water bodies equal to -0.09 , and based on their previous experience they suggest that this value includes mixed pixels. In our study we used a threshold of 0.5 to calculate open-water pixels from the SPOT MNDWI image. This threshold is slightly larger than the recommended by Ji et al. (2009): values greater than cero to detect water from SPOT 5 MNDWI data. Figure $10 \mathrm{c}$ ) shows the SPOT 5 MNDWI image, with the SPOT mixed-water pixels highlighted in red colour and a black square contour corresponding to a Landsat pixel classified as mixed-water containing nine SPOT pixels. 
Figure $10 \mathrm{~d}$ ) presents in cyan colour the SPOT MNDWI pixels classified as open-water within the region delineated as mixed pixels in a Landsat 8-OLI coarser classification. This classification was also revised by visual analysis over a SPOT composite (322), in which the lagoon boundaries are clearly defined. The black square contour in Figure $10 \mathrm{~d}$ ), corresponding to the mixed-waterclassified Landsat pixel centered at $30^{\circ} 02^{\prime} 57.86^{\prime}$ ' $\mathrm{S}, 62^{\circ} 38^{\prime} 19.48^{\prime \prime} \mathrm{W}$, shows that the presence of $100 \mathrm{~m}^{2}$ of open water (a SPOT-pixel area), which corresponds to $11 \%$ of a Landsat pixel area, is enough to detect a Landsat mixed-water pixel using the thresholds from Table 3. This result is consistent with the MNDWI simulation (Figure 9) suggesting a minimum of about $9 \%$ of openwater content to classify mixed pixels according to Table 3. To round off, a L8-OLI pixel centered at $30^{\circ} 02^{\prime} 55.26^{\prime}, \mathrm{S}, 62^{\circ} 38^{\prime} 16.13$ ' W $\mathrm{W}$ containing six open-water-classified SPOT pixels (66 \% of its area, just below the limit of $76 \%$ deducted from Figure 9) is also classified as mixed-water.

a)

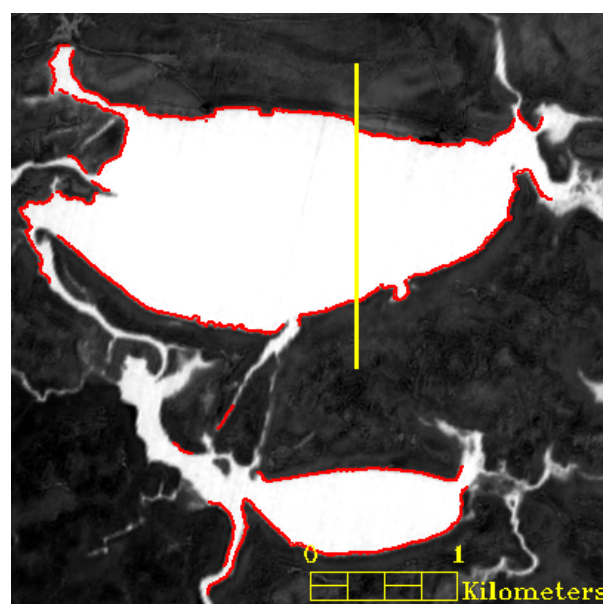

c)

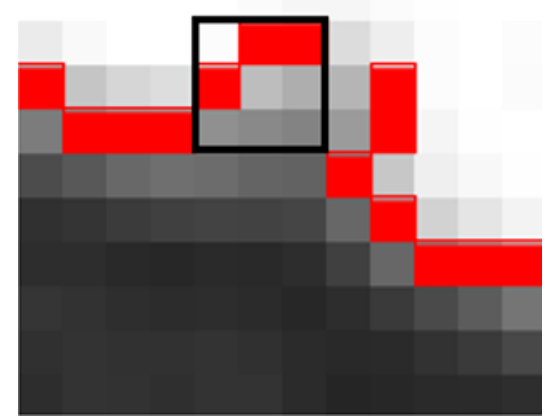

b)

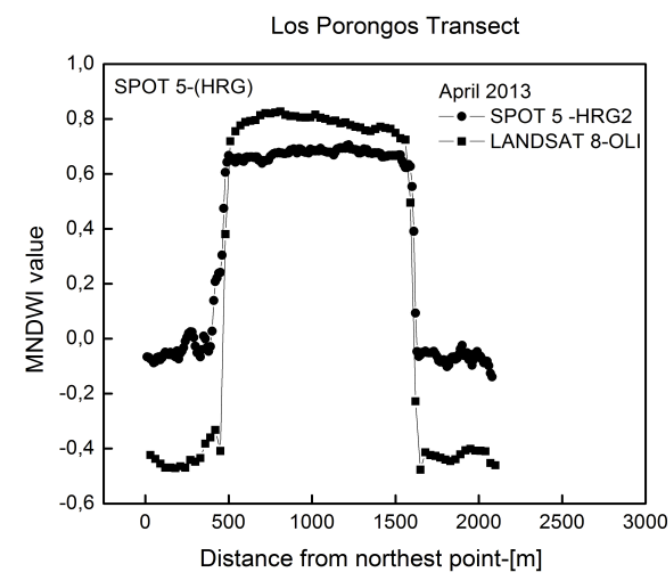

d)

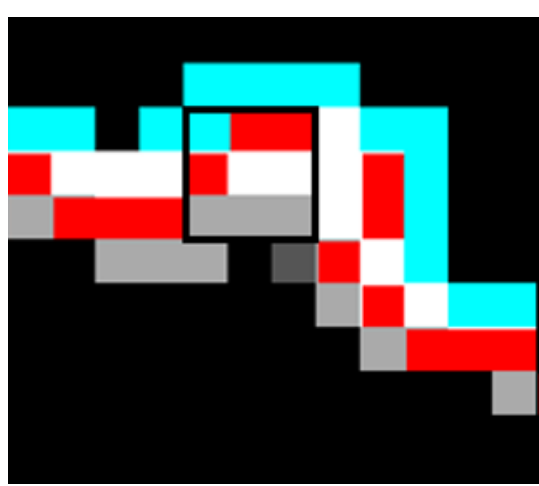


Figure 10. a) SPOT 5-HRG2 MNDWI image calculated for Los Porongos lagoon region. Red points correspond to mixed-water pixels selected as ground truth for the validation process. b) SPOT-5 and Landsat 8 MNDWI values as a function of distance along Los Porongos transect (yellow line). c) SPOT 5 MNDWI image with mixed-water pixels in red colour and a selected Landsat 8 mixed-water pixel (black square contour, centered at $30^{\circ} 02^{\prime} 57.86^{\prime}$ ' S, $62^{\circ} 38^{\prime} 19.48^{\prime \prime} \mathrm{W}$ ). d) The same Landsat 8 mixed-water-classified pixel, shows that it contains only one SPOT open-water-classified pixel (highlighted in cyan colour), in the lower limit deducted from Figure 9.

\subsubsection{Context with similar works}

In a recent study, Acharya et al. (2018) compared five methods, based on water spectral indices, to infer flooded areas in Nepal, finding that MNDWI is reliable to detect mixed pixels of small ponds and rivers but unable to detect snow cover and shadows in the Himalayas, errors that are absent in our study zone, free of shadows and snow. They did not discriminate between mixed pixels and open-water to classify water bodies and they proposed an optimal threshold equal 0.35 , which is consistent with our results but would overestimate the open-water area in our region. Feyiza et al. (2014) performed a thorough study of water indices evaluation with Landsat 5-TM imagery and proposed a new one. They have also demonstrated that a MNDWI threshold equal to 0.5 to classify open-water pixels presents an accuracy of $81 \%$, containing inside at least $50 \%$ of detectable open water. In our study zone, pixels with $50 \%$ of water content are classified as mixed within a $94 \%$ of confidence using the same threshold. Martins et al. (2018) evaluated the surface water change and turbidity variability of Sobradinho reservoir in northern Brazil during drought years, from 20132017, by analysing Landsat 8-OLI time series. They classified pixels as open-water if the MNDWI> 0 and NDVI $<0$ and they did not include mixed pixels in their analysis. However, the threshold value equal to zero was determined on a preliminary assessment over five land-cover categories, i.e. clear water, turbid water, vegetation, soil/sand and urban surfaces. In addition, they present box-plot analysis of MNDWI index values for clear and turbid open-water covers which are concentrated over 
0.5 , in agreement with the results of the present work. The review by Boschetti et al. (2014) compares the performance of several water indices for MODIS sensor, finding that MNDWI, calculated from band 4 (Green) and band 6 (SWIR) showed the best performance, proposing a threshold for open water equal to -0.228 . In that case, according to a second order adjustment between MNDWI and water content with a determination coefficient equal to 0.59 , that value would indicate near $40 \%$ of water content inside a pixel. They have demonstrated that MNDWI index presents the third best performance among VIR/SWIR and VIS/NIR indices to detect open-water pixels. Finally, Fisher et al. (2016) evaluated six different water indices, including MNDWI, to perform automatic water body extraction in eastern Australia. They demonstrated, based on long term data, that all indices and thresholds perform consistently across images from different Landsat sensors (TM, ETM+ and OLI) facilitating the automated classification of water bodies to similar levels of accuracy for the growing archive of Landsat data, consistently with the results of the present work. Finally, Crétaux et al. (2016) proposed methodological approaches to monitor lake-volume from space, particularly by SAR altimetry measurements, using also MNDWI index applied to Landsat 5-TM and MODIS sensors to infer lake areas. They established that final conclusions will depend on the methodology employed and the study zone delineation, emphasizing the need of validation with ground observations if available. In this framework, we had also performed a field campaign simultaneously with a Landsat 8-OLI overpass to assess the precision of the classification.

\subsubsection{Photographic field assessment}

In-situ GPS-georeferenced digital photographic registers were taken at many sites in a field itinerary along a Northwest zone of the Nature Reserve (see Figure 1-right) during morning hours of day 06 April 2015, simultaneous to a Landsat 8 overpass, for different ground conditions including 
dry and wet soil, pure vegetation, mixed areas with different proportions of water, and open-water lagoons, which are used as a complement to validate the satellite image classification. The sky was partially cloudy with sparse cumulus (total cloud cover of the whole Landsat scene: $8 \%$ ). Then, digital pictures taken at sites where the Landsat 8 scene presented neither cloud nor cloud shadow were selected for the comparison.

Figure 11 presents examples of the photographic validation showing very good agreement with the MNDWI thresholds defined for satellite pixel classification, under the three ground conditions we need to distinguish within a wetland region: open water pixels, mixed pixels with different proportions of observed water, and non-water pixels. It can be observed that the defined mixed water pixels range within $-0.35<\mathrm{MNDWI}<0.5$ for $\mathrm{L} 8$-OLI is in fact appropriate, given that pixels mostly covered by mud, vegetation and soil have MNDWI values just below the threshold of 0.35. Even though no similar photographic registers are available in previous years, the L5-TM MNDWI thresholds were established with the same criteria as seen in Figures 4 and 5, and the limit MNDWI $=0.4$ to separate mixed-water from open-water pixels for L5-TM was selected as the minimum MNDWI value assuring that the interior of Los Porongos lagoon being classified as openwater. Note that the third photo from left column is classified as non-water, even when it presents some observed water that, as shown, does not cover the minimum of $9 \%$ of observed open water necessary to classify a pixel as mixed-water $\left(81 \mathrm{~m}^{2}\right.$ over the $900 \mathrm{~m}^{2}$ of a Landsat pixel), supported by the high resolution image analysis which revealed an omission error of only $6.4 \%$ in detection of mixed-water pixels (Table 5). Additionally, the MNDWI value for this pixel (-0.379) is very close to the MNDWI value for the fourth photo from left column (-0.370) which corresponds definitely to non-water (prevailing mud with sparse vegetation), ratifying the reliability of the range $-0.35<$ MNDWI to separate non-water from mixed-water pixels. 


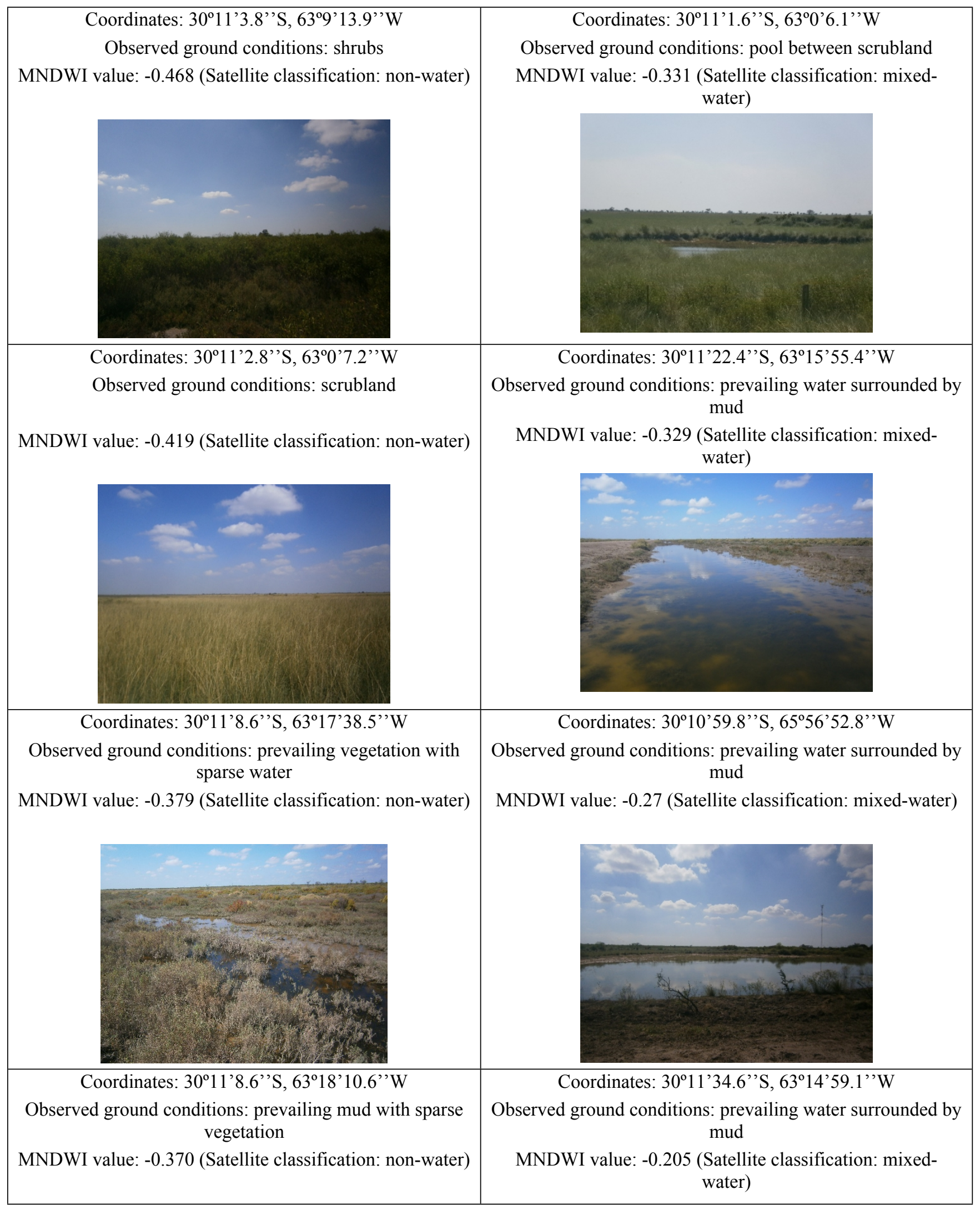




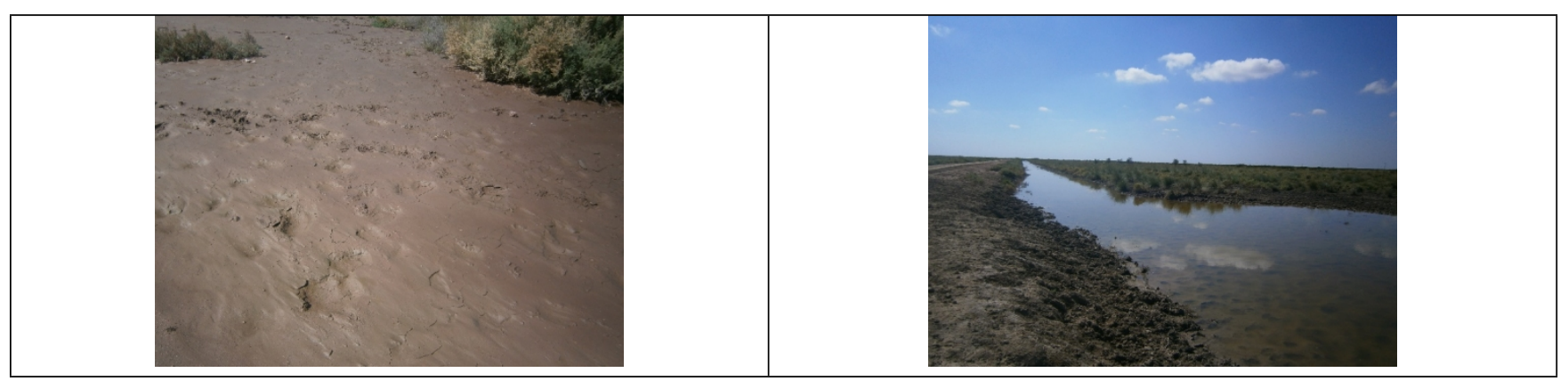

Figure 11. Examples of field validation of the Landsat 8 MNDWI values obtained from a L8 scene with date 06 April 2015, particularly for non-water and mixed-water pixels, compared with eight geo-referenced digital photographic registers simultaneous to the L8 overpass taken during a field campaign along a Northwest zone (demarcated in Figure 1-right) within the Nature Reserve. Results ratify the MNDWI ranges defined in Table 3.

\subsection{Flooded-area variability analysis}

As mentioned above, a total of sixteen Landsat mosaics (Table 2) covering the Dulce River wetlands and Mar Chiquita Lake Nature Reserve region in Argentina were analyzed spanning the period 2003-2017. Figure 12 shows examples of them. Figure 12-top is in real colour (RGB-321 for L5-TM, years 2003 and 2010, and RGB-432 for L8-OLI, years 2013 and 2015). Figure 12-bottom highlights in black colour the presence of open water, and in light gray the mixed-water pixels within the Dulce River wetlands under study (see Figure 1-right), with the Nature Reserve contour and Mar Chiquita Lake area demarcated in dark gray tone. 

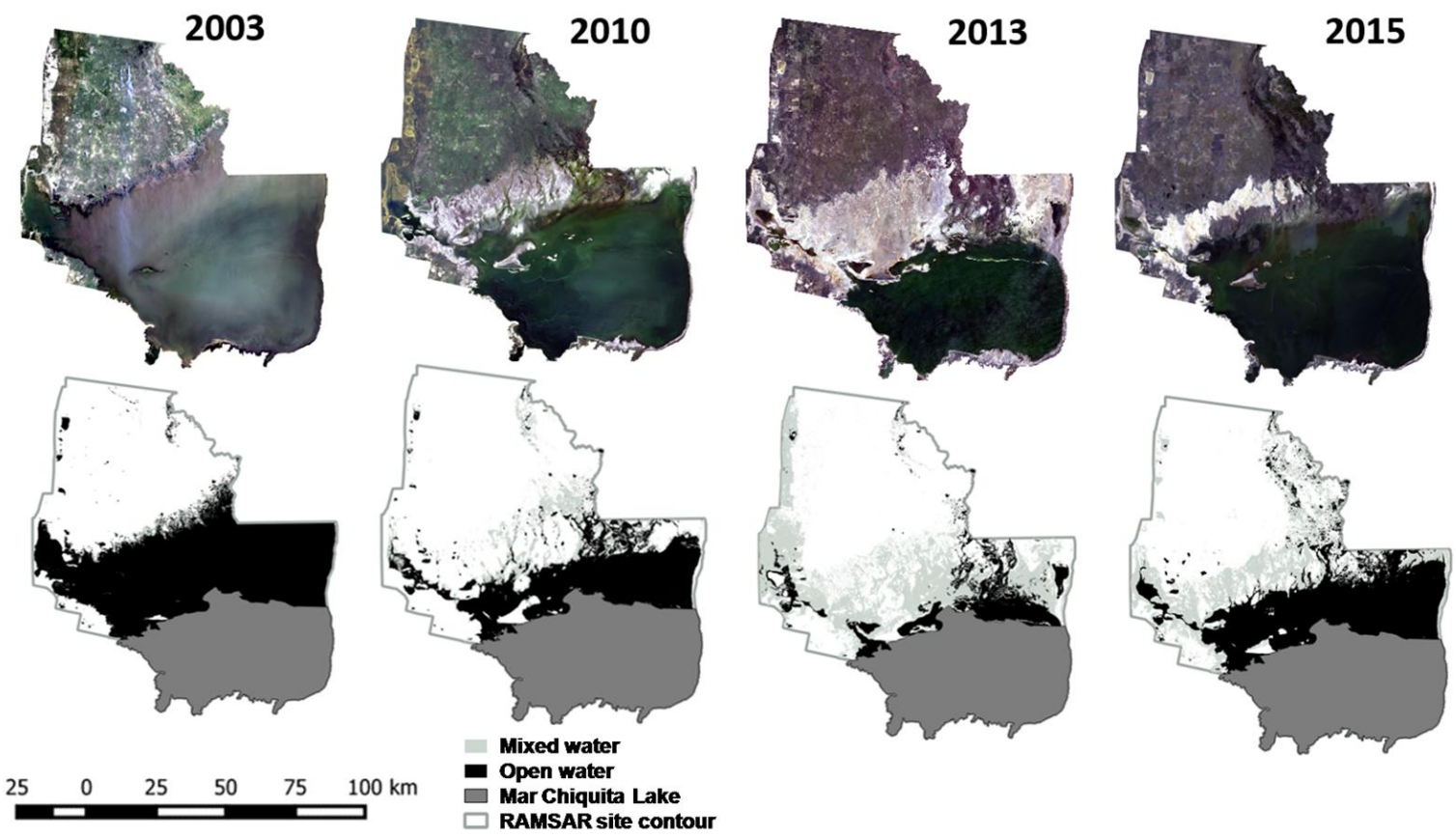

Figure 12. The Dulce River wetlands and Mar Chiquita Lake Nature Reserve in Argentina contoured from mosaics of available cloudless-sky Landsat satellite images dated in December 2003, February 2010, April 2013 and September 2015. Top: real colour (RGB-321 for L5-TM, years 2003 and 2010, and RGB-432 for L8-OLI, years 2013 and 2015). Bottom: open-water bodies within the Dulce River wetlands are highlighted in black colour and mixed-water pixels in light gray colour, while dark gray tone denotes the Nature Reserve contour and defined filled area of Mar Chiquita Lake at a level of 66 m asl.

Figure 13-left shows the time evolution of the satellite-retrieved extension of open-water, mixed-water and total (open+mixed) flooded area during the analyzed period 2003-2017, together with the locally-measured average water level of Mar Chiquita Lake for the same dates. Open-water and water level follow a strongly correlated behavior, as it is analyzed in detail in Figure 13-right. Total-water shows its maximum covered area around 2003-2005 with about $3600 \mathrm{~km}^{2}$. Open-water area reduced $86 \%$ from $3448.54 \mathrm{~km}^{2}$ in 2003 (the year of maximum recorded open-water extension with an average water level of $71.8 \mathrm{~m}$ asl in May 2003) down to $478.57 \mathrm{~km}^{2}$ by the end of 2013 (when average water level reached a minimum around $67.5 \mathrm{~m}$ asl). As it is expected for a flat basin, the reduction in the area initially covered by open water pixels due to different processes (e.g. hydrological deficit, evaporation in absence of rain, absorption by the soil) implies that many of them change to an intermediate condition of mixed-water, increasing the fraction covered by mixed water 
pixels within the same area simultaneously, and the reduction in the area covered by open water implies an increase in the area covered by mixed water as shown in Figure 13-left. However, this increase in the area covered by mixed water has two well defined periods. Even though the openwater covered area diminishes constantly in the period 2003-2013, mixed water shows a slowly rather linear increase from 2003 to 2011 followed by a sudden increase from 2011 to 2013 when it reaches their maximum. In turn, 2011 agrees with the date when the total water (open+mixed) reaches their minimum $\left(2056.1 \mathrm{~km}^{2}\right)$ and their recovery starts at a rather constant rate until 20152017 with an extension of about $3400 \mathrm{~km}^{2}$, when the Mar Chiquita Lake water level (see Figure 2) reaches $69.80 \mathrm{~m}$ asl in September 2017. Then, period 2011-2013 is key to understand the phenomena: after a period (2003-2011) of negative hydrological balance by reduced contribution from the northern rivers, a positive hydrological balance started in 2011 when the northern rivers increased their caudal. The first result of this positive hydrological balance is the increase in the mixed-water areas from the north when water is starting to recover the region, even though openwater area still reduces during the period 2011-2013. After 2013, this increased caudal incorporates to the open-water area at the north of Mar Chiquita Lake which starts their recovery in detriment of the mixed-water that loses the area gained by the open-water, while the total-water area continues their increase until 2015-2017 with an area of about $3400 \mathrm{~km}^{2}$.
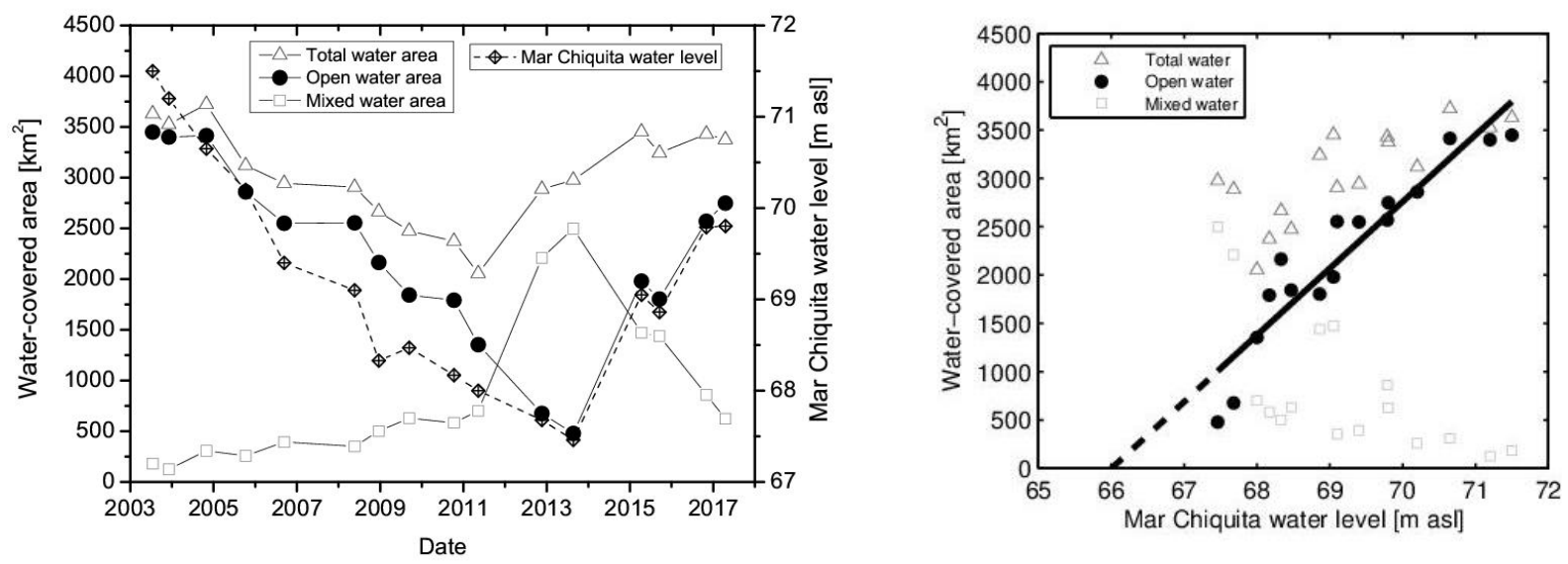
Figure 13. Left: Time evolution of the satellite-retrieved flooded-area extension within the Dulce River wetlands for the cases of mixed water, open water and total (mixed+open) water, and simultaneous locally-measured average water level of Mar Chiquita Lake during the period 20032017. Right: Satellite-retrieved flooded area within the Dulce River for open-water, mixed water and total water as a function of the average water level of Mar Chiquita Lake. Solid black line represents a linear fit to the open-water data, giving a slope $\mathrm{s}=690 \pm 72 \mathrm{~km} / \mathrm{m}$, while dashed black line is a linear extrapolation of the fitting down to zero flooded area, which would be reached for a water level of $66.0 \mathrm{~m}$ asl.

Figure 13-right shows that the area covered by open-water pixels is strongly linearly correlated (correlation coefficient $r=0.95, \mathrm{p}$-value $=6 \mathrm{e}-8$ ) with the Mar Chiquita Lake water level, different from the mixed water pixels $(r=-0.70, \mathrm{p}$-value $=4$ e-3 $)$ and the total flooded area $(r=0.77$, $p$-value $=7$ e-4). The resulting linear fit of open-water pixels as a function of Mar Chiquita Lake water level (coefficient of determination $r^{2}=0.90$ ) is consistent with two independent observations. Firstly, the linear extrapolation to zero-flooded-area within the Dulce River wetlands is obtained for a Mar Chiquita water level of $66.0 \mathrm{~m}$ asl, effectively the mentioned level of about $66 \mathrm{~m}$ asl that defines the Mar Chiquita Lake contour. Secondly, a slope $s=690 \pm 72 \mathrm{~km}^{2} / \mathrm{m}$ (at one standard deviation confidence level) is obtained in the linear fit. If the maximum flooded area in the Dulce River wetlands during year 2003 is approximated by a rectangular surface (in nadir view) with longest side $L \approx 80 \mathrm{~km}$, oriented slightly Southwest-Northeast as shown in Figure 14, it can be deducted that the topographical percentage slope $\alpha$ of the Dulce River mouth wetlands, idealized as a plain tilted terrain, is $\alpha=100 * L / s$. So, $\alpha \approx 0.012 \%$ is obtained in agreement with the value of $\alpha<$ $0.02 \%$ determined from bathymetric studies of the same area (Vargas, 2014). 
Figure 14. Simplified rectangular area of longest side $L=80 \mathrm{~km}$ (in nadir view) representing the
maximum extension of the open-water Dulce River wetlands flooded area over an idealized plain
tilted surface of percentage topographical slope $\alpha$, plotted over the satellite-retrieved open-water
flooded area (highlighted in black colour) during the maximum extension of year 2003 within the
Nature Reserve. Considering the slope $\mathrm{s}=690 \pm 72 \mathrm{~km}^{2} / \mathrm{m}$ of the linear fit from Figure 13-right, the

Figure 14. Simplified rectangular area of longest side $L=80 \mathrm{~km}$ (in nadir view) representing the
maximum extension of the open-water Dulce River wetlands flooded area over an idealized plain
tilted surface of percentage topographical slope $\alpha$, plotted over the satellite-retrieved open-water
flooded area (highlighted in black colour) during the maximum extension of year 2003 within the
Nature Reserve. Considering the slope $\mathrm{s}=690 \pm 72 \mathrm{~km}^{2} / \mathrm{m}$ of the linear fit from Figure 13-right, the

Figure 14. Simplified rectangular area of longest side $L=80 \mathrm{~km}$ (in nadir view) representing the
maximum extension of the open-water Dulce River wetlands flooded area over an idealized plain
tilted surface of percentage topographical slope $\alpha$, plotted over the satellite-retrieved open-water
flooded area (highlighted in black colour) during the maximum extension of year 2003 within the
Nature Reserve. Considering the slope $\mathrm{s}=690 \pm 72 \mathrm{~km}^{2} / \mathrm{m}$ of the linear fit from Figure 13-right, the

Figure 14. Simplified rectangular area of longest side $L=80 \mathrm{~km}$ (in nadir view) representing the
maximum extension of the open-water Dulce River wetlands flooded area over an idealized plain
tilted surface of percentage topographical slope $\alpha$, plotted over the satellite-retrieved open-water
flooded area (highlighted in black colour) during the maximum extension of year 2003 within the
Nature Reserve. Considering the slope $\mathrm{s}=690 \pm 72 \mathrm{~km}^{2} / \mathrm{m}$ of the linear fit from Figure 13-right, the

Figure 14. Simplified rectangular area of longest side $L=80 \mathrm{~km}$ (in nadir view) representing the
maximum extension of the open-water Dulce River wetlands flooded area over an idealized plain
tilted surface of percentage topographical slope $\alpha$, plotted over the satellite-retrieved open-water
flooded area (highlighted in black colour) during the maximum extension of year 2003 within the
Nature Reserve. Considering the slope $\mathrm{s}=690 \pm 72 \mathrm{~km}^{2} / \mathrm{m}$ of the linear fit from Figure 13-right, the resulting value is $\alpha \approx 0.012 \%$.

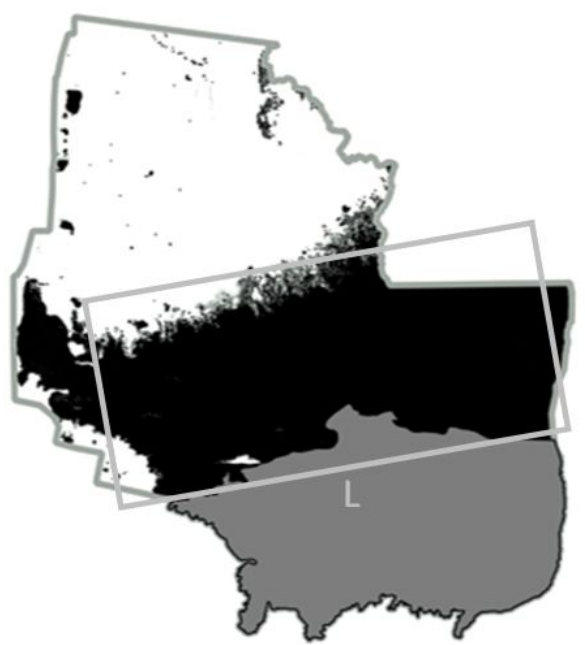




\section{Conclusions}

This work constituted a practical application of satellite data complemented by a set of locally-measured parameters and registers for analysis and validation, integrating scientific and official decision-maker institutions for monitoring, understanding and preservation of a wetland Nature Reserve of international relevance in Argentina. The water-covered surface area within the potentially flooded region of the Ramsar Nature Reserve Dulce River wetlands and Mar Chiquita Lake in Córdoba Province, Argentina, was retrieved from L5-TM and L8-OLI reflectance data by using the Modified Normalized Difference Water Index (MNDWI) on a total of 16 cloudless-sky mosaics in the period 2003-2017. As in every wetland region, the sensitivity of the satellite algorithm to detect areas partially covered by exposed water or with underlying water is crucial, and especial emphasis to correctly classify mixed-water pixels has been put in this work. Transects crossing two stable sub-regions, Los Porongos lagoon and a South branch of Mar Chiquita Lake, were used with the sixteen available image dates to define through box-plot analysis the MNDWI threshold values for each sensor to detect open-water pixels, mixed-water pixels and non-water pixels. To validate the established satellite MNDWI thresholds, a SPOT higher resolution satellite image was used, complemented by digital photographic registers taken within the Nature Reserve simultaneously to a Landsat 8 overpass, covering a diversity of zones with different proportion of observed water, assuring reliability in distinguishing mixed-water pixels. Additionally, an exhaustive linear mixture model analysis of the percentage of detectable open water inside a given Landsat pixel was made, ranging from $9 \%$ to $76 \%$ to be classified as a mixed-water pixel.

Maximum total flooded area extensions of about $3600 \mathrm{~km}^{2}$ during years 2003-2005 and a minimum one of $2050 \mathrm{~km}^{2}$ by the end of 2011 were determined. Supporting the known phenomenology of the region, the comparative evolution of open-water, mixed-water and total-water 
areas, and the Mar Chiquita Lake water level is highly compatible with an explanation that strongly relates the hydrological balance in the region with the caudal regime from the contributing northern rivers. The satellite-estimated open-water flooded area within the Dulce River wetlands shows a marked linear relation with the average locally measured water level of Mar Chiquita Lake. The extrapolation of the linear fitting to zero flooded area closely agrees with the water level of about 66 $m$ asl that defines the historical contour of Mar Chiquita Lake. Idealizing the Dulce River wetlands as a rectangular plain tilted surface, the slope of the linear fitting $\left(690 \mathrm{~km}^{2} / \mathrm{m}\right)$ leads to a terrain's topographical slope of $0.012 \%$, in agreement with the topographical slope $<0.02 \%$ obtained from bathymetric studies in the same area.

While the open-water flooded area within the Dulce River wetlands decreases systematically since 2003 down to the end of 2013, the total flooded-area reached its minimum by the end of 2011 , when a significant increase of the mixed-water area started. The detailed links of this behavior to the whole variables influencing the hydrological balance, climate parameters, chemical and physical water parameters, etc. in this complex endorheic system will be a subject of future work. The analysis of satellite imagery and correlations found in this work can be part of a management tutorial for government officials attending the preservation of the resources within this important Nature Reserve. The validated satellite method here provided constitutes a contributing tool to discriminate mixed-water from open-water pixels for monitoring different aspects of wetlands in the present climate change scenario. 


\section{Acknowledgements}

Special thanks to the United States Geological Survey for providing the Landsat 5 y Landsat 8 data, and to the Hydrological Resources Secretary of Córdoba Province, Argentina, for providing the official cartography of Mar Chiquita wetlands system, the locally-measured water level time series of Mar Chiquita Lake and photographic material used to validate the satellite images classification. The authors particularly acknowledge the collaboration of Inés Bernasconi from the Hydrological Resources Secretary, and the support from CONICET, CEPROCOR, CONAE and SeCyT from Cordoba National University, Argentina. We thank the certified English translator Cecilia Ferral from Blas Pascal University for the language revision. 


\section{References}

Acharya TD, DH Lee, IT Yang, JK Lee (2016) Identification of Water Bodies in a Landsat 8 OLI Image Using a J48 Decision Tree. Sensors 16 (7), 1075. doi: 10.3390/s16071075.

Boschetti M, Nutini F, Manfron G, Brivio PA and Nelson A (2014) Comparative analysis of normalised difference spectral indexes derived from MODIS for detecting surface water in flooded rice cropping systems.PloS one,9(2), e88741.

Bucher EH (1992) Population and conservation status of flamingos in Mar Chiquita, Córdoba, Argentina. Colonial Waterbirds 15: 179-184.

Bucher EH (ed.) (2006) Bañados del Río Dulce y Laguna Mar Chiquita (Córdoba, Argentina). Academia Nacional de Ciencias, Córdoba, Argentina.

Chen Y, Huang C, Ticehurst C, Merrin L, Thew P (2013) An evaluation of MODIS daily and 8-day composite products for floodplain and wetland inundation mapping. Wetlands 33: 823-835.

Congalton RG and K Green (1999). Assessing the Accuracy of Remotely Sensed Data: Principles and Practices. Lewis Publishers. 137 pp.

Crétaux_J-F, Abarca-del-Río R, Bergé-Nguyen M, Arsen A, Drolon V, Clos G, Maisongrande P (2016) Lake Volume Monitoring from Space. Surveys in Geophysics, pp 1-37.

Ferral A, Aleksinkó A, Plomer E, Orueta A, Cossano N, Bernasconi I, Díaz A, Scavuzzo M (2013) Detección de cambios temporales de superficie inundada en la zona de la Laguna de Mar Chiquita mediante imágenes satelitales. III Congreso Internacional de Ambiente y Energías Renovables, Villa María, Córdoba, Argentina, 44-53.

Feyisa GL, Meilby H, Fensholt R, and Proud SR (2014) Automated Water Extraction Index: A new technique for surface water mapping using Landsat imagery. Remote Sensing of Environment, 140, 23-35. 
Fisher A, Flood N and Danaher T (2016) Comparing Landsat water index methods for automated water classification in eastern Australia. Remote Sensing of Environment, 175, 167-182.

HGS (2016) Harris Geospatial Solutions - product documentation center.

http://www.exelisvis.com/docs/BackgroundOtherIndices.html

Ho TKL, Umitsu M, Yamaguchi Y (2010) Flood hazard mapping by satellite images and SRTM DEM in the Vu Gia - Thu Bon alluvial plain, central Vietnam. International Archives of the Photogrammetry, Remote Sensing and Spatial Information Science 38: 275-280.

Ho TKL, Yamaguchi Y, Umitsu M (2011) Significance of combining SRTM DEM and satellite images for generating automated micro-landform map. Geomorphometry 101-104. http:/geomorphometry.org/system/files/LoanHo2011 geomorphometry.pdf

Ji L, Li Z, Bruce W (2009) Analysis of dynamic thresholds for the normalized difference water index. Photogrammetric Engineering and Remote Sensing 75: 1307-1317. doi: https://doi.org/10.14358/PERS.75.11.1307.

Jones JW (2015) Efficient Wetland Surface Water Detection and Monitoring via Landsat: Comparison with in situ Data from the Everglades Depth Estimation Network. Remote Sensing 7: 12503-12538. doi: 10.3390/rs70912503.

Kosicki JZ, Chylarecki P (2013) Predictive mapping of Meadow Pipit density using integrated remote sensing data with Atlas of Vascular Plants dataset. Bird Study 60: 500-508.

Li L, Vrieling A, Skidmore A, Wang T, Muñoz AR, Turak E (2015) Evaluation of MODIS Spectral Indices for Monitoring Hydrological Dynamics of a Small, Seasonally-Flooded Wetland in Southern Spain. Wetlands 35:851-864. doi 10.1007/s13157-015-0676-9

Martínez DE (1995) Changes in the ionic composition of a saline lake, Mar Chiquita, Province of Córdoba, Argentina. International Journal of Salt Lake Research 4: 25-44.

Martins VS, Kaleita A, Barbosa CC, Fassoni-Andrade AC, de Lucia Lobo F and Novo EM (2018) Remote sensing of large reservoir in the drought years: Implications on surface water change 
Mitchell AL, Milne AK, Tapley I (2015) Towards an operational SAR monitoring system for monitoring environmental flows in the Macquarie Marshes. Wetlands Ecology and Management 23(1): 61-77.

Mozumder C, Tripathi NK, Tipdecho T (2014) Ecosystem evaluation (1989-2012) of Ramsar wetland Deepor Beel using satellite-derived indices. Environmental Monitoring and Assessment 186(11): 7909-7927. doi: 10.1007/s10661-014-3976-2.

Nores M (2011) Long-term waterbird fluctuations in Mar Chiquita Lake, central Argentina. Waterbirds 34: 381-388.

Ogilvie A, Belaud G, Massuel S, Mulligan M, Le Goulven P and Calvez R (2018) Surface water monitoring in small water bodies: potential and limits of multi-sensor Landsat time series. Hydrology \& Earth System Sciences, 22(8).

Piovano EL, Ariztegui D, Moreira S (2002) Recent environmental changes in Laguna Mar Chiquita (central Argentina): a sedimentary model for a highly variable saline lake. Sedimentology 49: 1371-1384.

Piovano EL, Ariztegui D, Bernasconi SM, McKenzie JA (2004) Stable isotopic record of hydrological changes in subtropical Laguna Mar Chiquita (Argentina) over the last 230 years. The Holocene 14: 525-535.

Plencovich GE (2011) Simulación hidrológica de los humedales de Mar Chiquita con apoyo satelital. Msc Dissertation. Universidad Nacional de Córdoba, Argentina.

Reati GJ, Florín M, Fernández GJ, Montes C (1996) The Laguna de Mar Chiquita (Córdoba, Argentina): a little known, secularly fluctuating, saline lake. International Journal of Salt Lake Research 5: 187-219. 
Sharma CS, Mishra A, Panda SN (2014) Assessing impact of flood on river dynamics and susceptible regions: Geomorphometric analysis. Water Resources Management 28(9): 26152638.

Stutz S, Prieto AR, (2003) Modern pollen and vegetation relationships in Mar Chiquita coastal lagoon area, southeastern Pampa grasslands, Argentina. Review of Palaeobotany and Palynology 126: 183-195.

Troin M, Vallet-Coulomb C, Sylvestre F, Piovano E (2010) Hydrological modelling of a closed lake (Laguna Mar Chiquita, Argentina) in the context of 20th century climatic changes. Journal of Hydrology 393(3): 233-244.

UN (2017) The Global Indicator Framework, adopted by the General Assembly on the Statistical Commission pertaining to the United Nations 2030 Agenda for Sustainable Development (A/RES/71/313).

Vargas C (2014) Análisis de la dinámica hídrica espacial de la Laguna Mar Chiquita período 20012014 (Bachelor's thesis, Universidad Nacional de Córdoba. Facultad de Ciencias Exactas, Físicas y Naturales.).

Verpoorter C, Kutser T and Tranvik L (2012) Automated mapping of water bodies using Landsat multispectral data. Limnology and Oceanography: Methods, 10(12), 1037-1050.

Vihervaara P et al. (2017) How Essential Biodiversity Variables and remote sensing can help national biodiversity monitoring. Global Ecology and Conservation 10: 43-59.

Wang B, Chen Y, Lü C (2015) Evaluating flood inundation impact on wetland vegetation FPAR of the Macquarie Marshes, Australia. Environmental Earth Sciences 74(6): 4989-5000.

Xiao X, Wdowinski S, Wu Y (2014) Improved Water Classification Using an Application-oriented Processing of Landsat ETM+ and ALOS PALSAR. International Journal of Control and Automation 7(11): 355-370. http://dx.doi.org/10.14257/ijca.2014.7.11.35 
$\mathrm{Xu} \mathrm{H}$ (2006) Modification of normalised difference water index (NDWI) to enhance open water features in remotely sensed imagery. International Journal of Remote Sensing 27: 3025-3033.

Xu-kai Z, Quiong-quiong L, Baig A, Hassan M (2012) Automated detection of coastline using Landsat TM based on water index and edge detection methods. Second International Workshop on Earth Observation and Remote Sensing Applications 153-156. 